\title{
Acute Mesenteric Ischemia Diagnosed after Emergent Single-Balloon Enteroscopy
}

\author{
Ana Catarina Gomes Rolando Pinho Jaime Pereira Rodrigues Mafalda Sousa \\ João-Carlos Silva João Carvalho \\ Department of Gastroenterology, Centro Hospitalar de Vila Nova de Gaia/Espinho, Vila Nova de Gaia, Portugal
}

\section{Keywords}

Acute mesenteric ischemia - Jejunum .

Emergent single-balloon enteroscopy · Enteroscopy

\section{Isquemia mesentérica aguda diagnosticada após enteroscopia de mono-balão emergente}

\section{Palavras Chave}

Isquemia mesentérica aguda · Jejuno · Emergente • Enteroscopia

A 57-year-old woman presented to the emergency department with a 2-day history of progressive abdominal pain with vomiting and hematochezia in the last $12 \mathrm{~h}$. There was no relevant personal or familial history, besides major depression. On physical examination, the patient presented tachycardia (110/min), as well as abdominal tenderness and distension. Laboratory studies revealed leukocytosis (white-cell count of $21,000 / \mathrm{mm}^{3}$ ), metabolic acidosis $(\mathrm{pH}=7.21)$, and elevated serum lactate $(7.5 \mathrm{mmol} / \mathrm{L})$. Since a dark hematic content was pres-

\section{KARGER}

E-Mail karger@karger.com www.karger.com/pjg
(C) 2018 Sociedade Portuguesa de Gastrenterologia Published by S. Karger AG, Basel

Karcer

Open access

This article is licensed under the Creative Commons Attribution NonCommercial-NoDerivatives 4.0 International License (CC BYNC-ND) (http://www.karger.com/Services/OpenAccessLicense). Usage and distribution for commercial purposes as well as any distribution of modified material requires written permission. ent in the nasogastric tube, an upper gastrointestinal endoscopy was deemed necessary. In the upper gastrointestinal endoscopy, dark blood was visualized in the esophagus and stomach, whereas fresh blood was present in the duodenum. After thorough washing and aspiration, no active bleeding nor lesions were found up to the 4th part of the duodenum, but fresh blood was noted refluxing from the jejunum. An emergent single-balloon enteroscopy was performed, which showed distal to the angle of Treitz, congestive mucosa with hemorrhagic suffusions, dark coloration, circumferential ulcers, and spontaneous bleeding (Fig. 1, 2a-d), consistent with acute mesenteric ischemia (AMI). Computed tomography (CT) revealed total portal vein thrombosis extending from the superior mesenteric vein (Fig. 3a, b). The patient underwent emergent laparotomy. All of the jejunum and ileum was found to be necrotic during surgery; hence, no bowel was resected. The patient eventually died after surgery.

AMI is defined as a sudden arterial or venous occlusion or a drop in the circulating pressure resulting in inadequate blood flow within the mesenteric circulation to meet the metabolic demands [1]. AMI is classified into four groups according to its etiology: arterial embolism of 
1

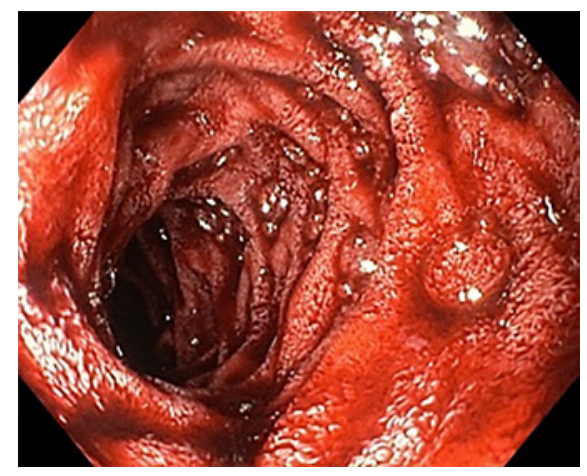

Fig. 1. Endoscopic picture showing fresh blood in the small bowel.

Fig. 2. a-d Endoscopic pictures showing congestive mucosa, with hemorrhagic suffusions, dark coloration, circumferential ulcers, and spontaneous bleeding.

\section{2}
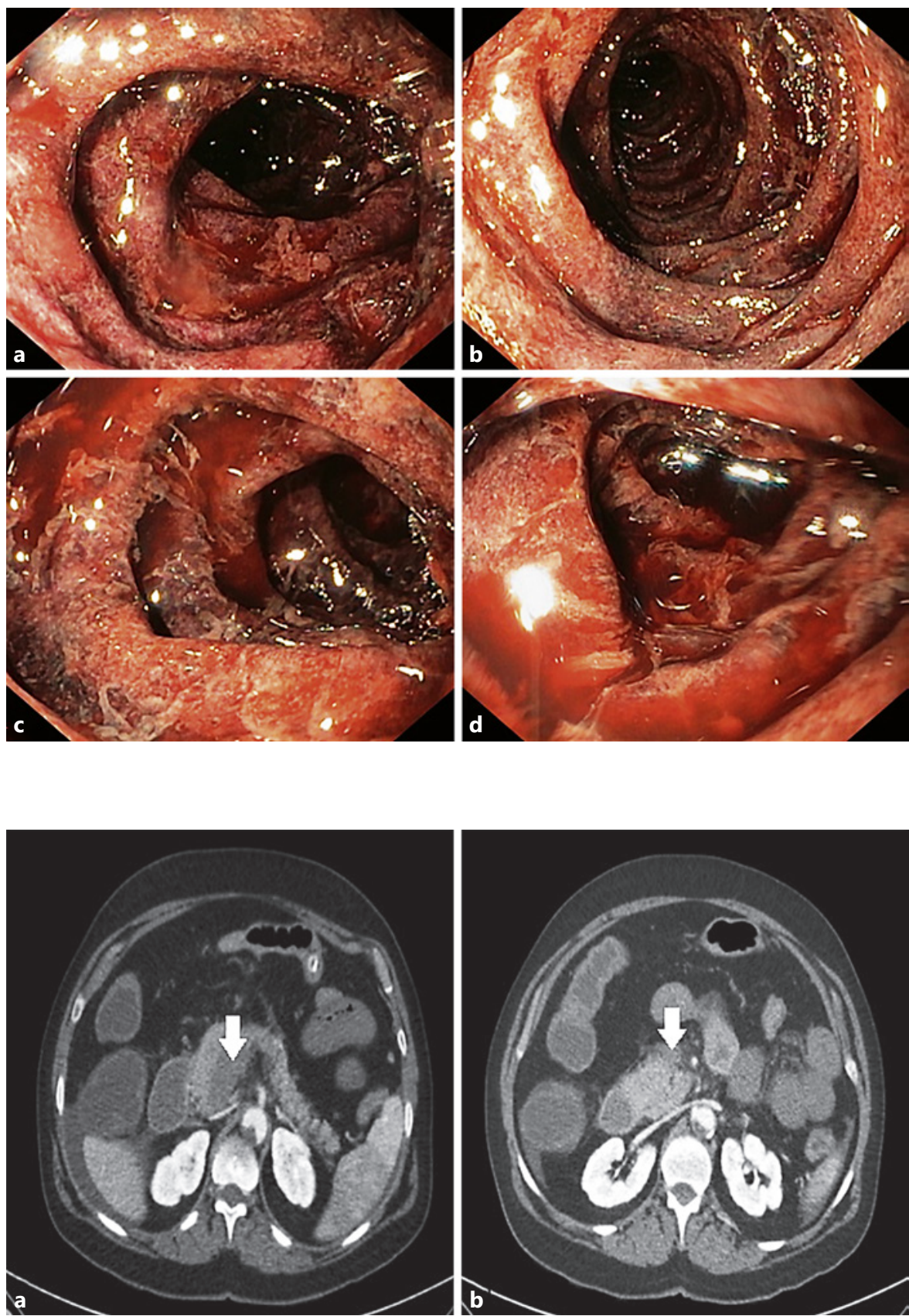

Fig. 3. CT images. a Thrombus in the portal vein. $\mathbf{b}$ Thrombus in the superior mesenteric vein.

arterial spasm and transmural bowel infarction within days to weeks [3]. MVT can be classified as idiopathic or secondary. Ninety percent of cases are due to secondary causes, related to an underlying hypercoagulable state, neoplasia, oral contraceptive use, trauma, or intra-abdominal inflammatory conditions [2]. These patients typically present with more insidious and less severe pain than those with arterial occlusion. White blood cell count, lactate, and metabolic acidosis are classic serum markers 
for AMI $[2,4]$. When this condition is suspected, CT should be performed with contrast enhancement in arterial and venous phases (the biphasic protocol), since failure to recognize AMI before intestinal necrosis has developed is responsible for the high mortality of the disease [3]. Although emergent device-assisted enteroscopy, defined as enteroscopy performed in the first $24 \mathrm{~h}$ of presentation, is not widely implemented, there is evidence that its early use results in an increased diagnostic and therapeutic yield [5]. In this case, although an early diagnosis was possible, the severity of the condition precluded an improved outcome.

\section{Disclosure Statement}

The authors have no conflicts of interest to declare.
1 Tilsed JV, Casamassima A, Kurihara H, Mariani D, Martinez I, Pereira J, Ponchietti L, Shamiyeh A, Al-Ayoubi F, Barco LA, Ceolin M, D’Almeida AJ, Hilario S, Olavarria AL, Ozmen MM, Pinheiro LF, Poeze M, Triantos G, Fuentes FT, Sierra SU, Soreide K, Yanar H: ESTES guidelines: acute mesenteric ischaemia. Eur J Trauma Emerg Surg 2016;42:253-270.

2 Clair DG, Beach JM: Mesenteric Ischemia. N Engl J Med 2016;374:959-968.

3 Karkkainen JM, Acosta S: Acute mesenteric ischemia (part I) - incidence, etiologies, and how to improve early diagnosis. Best Pract Res Clin Gastroenterol 2017;31:15-25.

4 Carver TW, Vora RS, Taneja A: Mesenteric ischemia. Crit Care Clin 2016;32:155-171.

5 Pinto-Pais T, Pinho R, Rodrigues A, Fernandes C, Ribeiro I, Fraga J, Carvalho J: Emergency single-balloon enteroscopy in overt obscure gastrointestinal bleeding: efficacy and safety. United European Gastroenterol J 2014;2:490-496 